\title{
BIOMASSA DE RAÍZES E REGIME HÍDRICO DO SOLO EM PLANTIO DE Pseudosamanea guachapele (Kunth) Harms EM UM PLANOSSOLO HÁPLICO
}

\author{
Fabiano de Carvalho Balieiro*, Marcos Bacis Ceddia**, Marcos Gervásio Pereira**, \\ Alexander Silva Resende***, Avílio Antônio Franco**** \\ * Eng. Agrônomo, Dr., UFRRJ - PRODOC/CAPES - carvalieiro@ufrrj.br \\ ** Eng. Agrônomo, Dr., Dep. de Solos, UFRRJ - ceddia@ufrrj.br-gervasio@ufrrj.br \\ *** Eng. Florestal, Dr., Embrapa Agrobiologia, RJ - alex@cnpab.embrapa.br \\ **** Eng. Agrônomo, Dr., Embrapa Agrobiologia, RJ - avilio@cnpab.embrapa.br \\ Recebido para publicação: 26/10/2004 - Aceito para publicação: 07/07/2005
}

\begin{abstract}
Resumo
Biomassa de raízes e regime hídrico do solo em plantio de Pseudosamanea guachapele (Kunth) Harms num Planossolo Háplico. Objetivou-se com este estudo quantificar a biomassa e a distribuição de raízes, bem como o regime hídrico do solo num plantio de Pseudosamanea guachapele com sete anos. A leguminosa acumulou, nas raízes, $8,8 \mathrm{~kg}^{\mathrm{r} r v o r e}{ }^{-1}$ (ou 29,5 $\mathrm{Mg} \mathrm{ha}^{-1}$ ) de biomassa seca, sendo que $57 \%$ representavam a raiz pivotante e o restante $(43 \%)$ as raízes mais finas e laterais. Cerca de $70 \%$ da massa de raízes mais finas encontravam-se nos 20 primeiros $\mathrm{cm}$ de profundidade. As variações na umidade tenderam a se reduzir em profundidade. A maior recarga em profundidade próximo ao tronco da espécie indica possível contribuição do escoamento pelo tronco da água da chuva.

Palavras-chave: Distribuição de raízes; alocação; retenção de água no solo; leguminosa arbórea.
\end{abstract}

\section{Abstract}

Root biomass and soil water regime in Pseudosamanea guachapele (Kunth) Harms plantation. This research intended to quantify root biomass and analyze its distribution, as well as soil water regime on a seven years old Pseudosamanea guachapele plantation. The leguminosae tree accumulated in its roots $8.8 \mathrm{~kg} \mathrm{plant}^{-1}$ (or $29.5 \mathrm{Mg} \mathrm{ha}^{-1}$ ) of biomass, $57 \%$ in tap root and $43 \%$ in lateral thin roots. Thin roots were located preferentially at the first $20 \mathrm{~cm}$ underground. Volumetric humidity variations tended to decrease the more the depth. The most evident concentration on depth of water near the trunk indicates possible contribution of rain water flowing through the stem.

Keywords: Root distribution; allocation; soil water retention; leguminosae tree.

\section{INTRODUÇ̃̃O}

A maioria das espécies leguminosas arbóreas, principalmente aquelas das subfamílias Papilinoideae e Mimosoideae, é capaz de formar simbiose eficiente com bactérias diazotróficas (Faria et al., 1999). Devido a essa associação, diversas espécies da família têm sido utilizadas como condicionadoras de solos ácidos e de baixa fertilidade, como os solos tropicais. Além de algumas espécies apresentarem baixa exigência nutricional e tolerância à acidez do solo (Dias et al., 1990; Dias et al., 1991; Fernandez et al., 1996; Balieiro et al., 2001a) por meio da simbiose formada, os sistemas de produção podem se beneficiar da fixação biológica de $\mathrm{N}_{2}$, por esta (a) dispensar (total ou parcialmente) a aplicação do fertilizante nitrogenado, cuja produção exige grande requerimento energético $(14.700 \mathrm{kcal}$ por $\mathrm{kg}$ de $\mathrm{N}$ fertilizante) (Macedo e Koller, 1997); (b) diminuir o potencial de poluição e de perdas dos fertilizantes nitrogenados, uma vez que o sincronismo entre os organismos simbiontes é perfeitamente atendido se fatores limitantes à simbiose são satisfeitos (Siqueira e Franco, 1988); (c) aumentar o estoque de nutrientes e $\mathrm{C}$ do solo, seja por deposição direta da serapilheira sobre o solo de material rico em $\mathrm{N}$ ou estabilização da matéria orgânica do solo (Sisti et al., 2003); (d) aumentar a solubilização de fosfatos naturais (Jesus, 1993), fontes mais baratas de P; e (e) introduzir no sistema quantidades significativas de N (Peoples e Craswell, 1992). 
A associação dessas espécies com fungos micorrízicos aumenta a absorção de água e nutrientes de baixa mobilidade do solo, como o $\mathrm{P}$ e o $\mathrm{Zn}$, aumentando a tolerância das mesmas ao estresse hídrico e às condições adversas do meio (Siqueira e Franco, 1988; Awotoye et al., 1992; Franco e Faria, 1997).

Pseudosamanea guachapele (guachapele) é uma leguminosa arbórea fixadora de $\mathrm{N}_{2}$ atmosférico, nativa da América Central e México, que tem mostrado boa adaptação nas condições edafoclimáticas do sudeste brasileiro. Com uma elevada capacidade de ciclar nutrientes, via queda de serapilheira e decomposição de seus resíduos no solo (Froufe, 1999; Balieiro et al., 2004), a espécie surge como alternativa interessante ao manejo de solos com baixa fertilidade.

Embora essas informações estejam mostrando que a espécie tem potencial para ser utilizada em sistemas agroflorestais e programas de recuperação de áreas degradadas, nenhuma informação a respeito da distribuição e do acúmulo da biomassa radicular da espécie é encontrada na literatura. Como evidenciado anteriormente é imprescindível que se conheçam as estratégias de uso e exigências das espécies quanto à água, nutrientes e luz, para que arranjos de plantios sejam delineados em harmonia com o manejo sustentável dos solos.

Esse trabalho avaliou (i) a distribuição e a acumulação de biomassa das raízes e (ii) a variação da umidade em um Planossolo Háplico sob um plantio experimental de guachapele.

\section{MATERIAL E MÉTODOS}

\section{Descrição da área}

O trabalho foi realizado no Campo Experimental da Embrapa/Agrobiologia, situado a $33 \mathrm{~m}$ de altitude, no município de Seropédica, Rio de Janeiro ( $22^{\circ} 46^{\prime}$ de latitude sul e $43^{\circ} 41^{\prime}$ de longitude oeste). A média pluviométrica anual é de $1.250 \mathrm{~mm}$ e a temperatura varia de $16{ }^{\circ} \mathrm{C}$ (entre junho e julho) a $32^{\circ} \mathrm{C}$ (entre os meses de janeiro e março). A umidade relativa média anual é de $73 \%$.

O solo pertence à série Ecologia, ordem dos Planossolos Háplicos (Ramos et al., 1973; Embrapa, 1999). As principais características desse solo são a presença de horizontes superficiais (A e E) de textura variando de areia a areia franca, sendo que na área de estudo esses horizontes possuem profundidades superiores a 1,30 m. Além dessa característica, o solo possui baixa capacidade de troca catiônica (valores inferiores a $27 \mathrm{cmol}_{\mathrm{c}} \mathrm{kg}_{\text {argila }}{ }^{-1}$ ) e baixos teores de matéria orgânica e nutrientes.

Antes da implantação do experimento, foi realizada uma amostragem prévia do solo (em 1993),

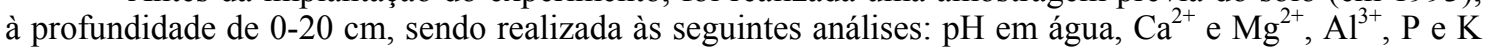
(Embrapa, 1997). Os resultados da análise química são apresentados na Tabela 1.

Tabela 1. Valor de pH e características químicas da camada superficial $(0-20 \mathrm{~cm})$ do Planossolo. Table 1. $\mathrm{pH}$ and chemical characteristcs of a Planossol top layer $(0-20 \mathrm{~cm})$.

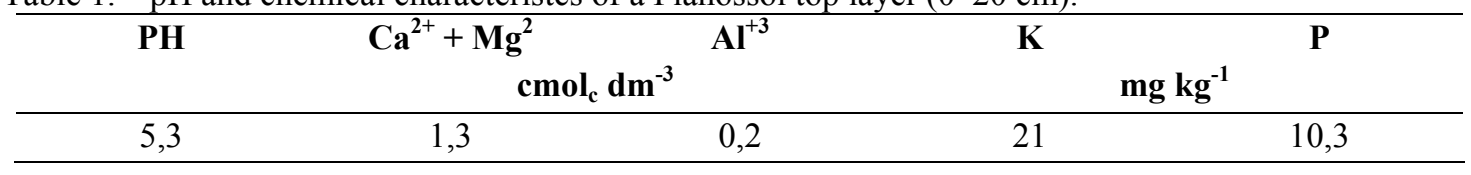

A área apresenta relevo variando de plano (0-3\% de declividade) a suave ondulado (3-8\% de declividade) e foi utilizada como pastagem por mais de 10 anos antes que os plantios fossem estabelecidos.

\section{Inoculação das sementes e plantio}

Um plantio puro de guachapele de $2.500 \mathrm{~m}^{2}$ foi realizado em 1993, com mudas de 3 meses de idade, com um espaçamento de $3 \times 1 \mathrm{~m}$. A inoculação das sementes da leguminosa (guachapele) foi feita com estirpes selecionadas de rizóbio (BR6205 e BR6821) recomendadas pela Embrapa Agrobiologia (Franco e Faria, 1997) e com esporos e hifas dos fungos micorrízicos Glomus clarum e Gigaspora margarita. No momento do plantio, cada cova recebeu $100 \mathrm{~g}$ de fosfato de rocha $+10 \mathrm{~g}$ de uma fonte de micronutrientes (FTE-Br-12). Após o plantio das espécies não foi realizado nenhum tipo de adubação.

\section{Avaliação da biomassa e distribuição das raízes}

Procedimento de amostragem

O procedimento de amostragem baseou-se na seleção de três árvores com diâmetros de tronco à altura do peito (DAP) próximos daqueles de árvores derrubadas para avaliação de biomassa de parte aérea, ou seja, 10,1 cm (Balieiro, 2002). Dessa forma, foi possível também estimar a relação raiz/parte 
aérea das árvores. Posteriormente, abriu-se uma trincheira, de modo que a primeira camada avaliada coincidisse com a entrelinha de plantio (letra a da Figura 1), ou seja a 1,5 $\mathrm{m}$ da linha de plantio. As demais avaliações foram feitas a 0,75 (letra b da Figura 1) e $0,10 \mathrm{~m}$ da árvore selecionada (letra $\mathbf{c}$ da Figura 1). A abertura era feita até que o tronco fosse alcançado, sendo posteriormente realizada a escavação para a avaliação da raiz pivotante (Letra d).

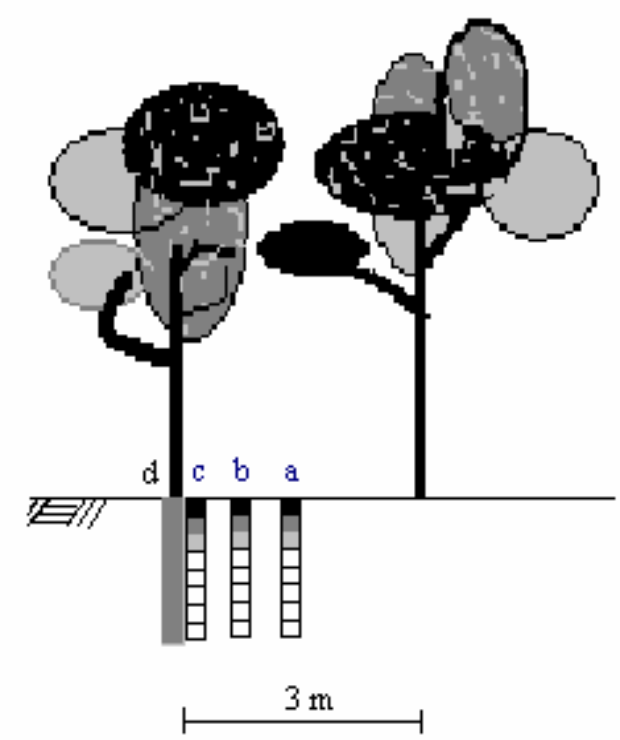

Figura 1. Ilustração do esquema de amostragem usado para estimativa da biomassa de raízes de guachapele.

Figure 1. Illustration of the sample used for measuring guachapele root biomass.

Em seguida, em cada ponto de amostragem foram coletadas amostras de dimensões de $0,50 \mathrm{x}$ $0,10 \times 0,10 \mathrm{~m}$ (comprimento $\mathrm{x}$ largura x profundidade), sendo estas retiradas até a profundidade de 0,80 $\mathrm{m}$, em intervalos regulares de $0,10 \mathrm{~m}$. Os resultados encontrados foram expressos através da relação massa de raízes/volume de solo.

Posteriormente, as amostras foram submetidas a um peneiramento em água, utilizando-se peneiras de $2 \mathrm{~mm}$, e as raízes classificadas quanto aos seus diâmetros, com a ajuda de um paquímetro, em três classes: $\leq 1 \mathrm{~mm}, 1$ a $5 \mathrm{~mm},>5 \mathrm{~mm}$.

\section{Determinação da densidade do solo}

Com o intuito de se identificar possíveis restrições de ordem física no solo em estudo, determinou-se a densidade do solo, segundo Embrapa (1997), em intervalos regulares de 0,1 m até 0,8 m de profundidade. Para tanto, foram retiradas três amostras na entrelinha de plantio, em cada profundidade, com o auxílio de um anel de aço com $99,3 \mathrm{~cm}^{3}$ de capacidade.

\section{Regime hídrico do solo}

A avaliação do regime hídrico do solo foi feita com o auxílio de uma sonda de nêutrons (modelo TROXLER 430). Foram instalados 6 tubos de alumínio com 1,0 $\mathrm{m}$ de comprimento na entrelinha de plantio, sendo as profundidades de leitura delimitadas a 0,2, 0,3, 0,5 e 0,8 m. Distando 0,2 $\mathrm{m}$ do tronco da árvore, 3 tubos com 1,2 $\mathrm{m}$ de comprimento foram também inseridos no solo para que o monitoramento do teor de água do solo se desse até a profundidade de $1,0 \mathrm{~m}$.

Devido à homogeneidade da área, uma curva de calibração foi confeccionada dentro do plantio, sendo a contagem de nêutrons atenuados, transformada para umidade volumétrica, conforme descrito por Bacchi e Reichardt (1990).

\section{Estimativa do potencial mátrico do solo}

O potencial mátrico do solo foi estimado através de curva característica de retenção de solução do solo (umidade versus potencial mátrico). Para cada profundidade de monitoramento da umidade, 
coletaram-se amostras indeformadas, as quais foram saturadas e colocadas em câmaras de pressão de Richards, onde se determinou a umidade nas seguintes pressões: 6, 10, 33, 100, 300, 500 e $1500 \mathrm{kPa}$. Com os dados pareados de umidade versus pressão, fez-se o ajuste de modelos matemáticos de curva de retenção de umidade, utilizando-se o programa Soil Water Retention Curve (Dourado Neto et al., 2000) para inferir o potencial mátrico nos intervalos de dados medidos. Os modelos que melhor se ajustaram aos dados foram escolhidos com base em análise de variância, coeficiente de determinação e soma do quadrado dos resíduos. Subamostras foram também caracterizadas quanto à granulometria.

\section{Análise estatística}

Os dados referentes à umidade do solo (regime hídrico) foram analisados por meio do teste $\mathrm{t}$ (dados pareados), sendo as comparações feitas dentro de cada profundidade separadamente e utilizando a distância do tronco como fonte de variação. Os dados de raízes não foram analisados estatisticamente.

\section{RESULTADOS E DISCUSSÃO}

\section{Características físico-hídricas do solo}

As propriedades físico-hídricas do solo (Tabela 2) são fortemente determinadas pela textura. Até a profundidade de $80 \mathrm{~cm}$ ocorre a classe textural areia, e de 80 a $100 \mathrm{~cm}$, areia franca. Os valores de densidade do solo e das partículas são característicos de solos de textura arenosa, que segundo Reichardt e Timm (2004), variam entre $1,40-1,80 \mathrm{~kg} \mathrm{dm}^{-3}$ e em torno de $2,65 \mathrm{~kg} \mathrm{dm}^{-3}$, respectivamente.

Tabela 2. Algumas características físico-hídricas dos horizontes do solo.

Table 2. Some physical and hydric characteristics of focused soil horizons.

\begin{tabular}{|c|c|c|c|c|c|c|c|c|c|c|}
\hline Horizonte & $\begin{array}{c}\text { Profundidade } \\
\text { (m) }\end{array}$ & $\begin{array}{r}\text { Areia } \\
--\end{array}$ & $\begin{array}{l}\text { Silte } \\
\mathrm{g} \mathrm{kg}^{-1}\end{array}$ & Argila & $D s^{(1)}$ & $\begin{array}{c}D p^{(2)} \\
\operatorname{kg~dm}^{-3}\end{array}$ & $\mathbf{P t}^{(3)}$ & $\begin{array}{c}\theta^{\mathrm{CC}(4)} \\
- \\
-\end{array}$ & $\begin{array}{c}\theta^{\text {PMP(5) }} \\
-\% \\
-0\end{array}$ & $\theta^{\mathrm{ADT}(6)}$ \\
\hline A & $0,0-0,20$ & 910 & 30 & 60 & 1,57 & 2,70 & 42 & 0,09 & 0,03 & 0,06 \\
\hline E1 & $0,20-0,32$ & 930 & 30 & 40 & 1,60 & 2,70 & 41 & 0,07 & 0,01 & 0,06 \\
\hline E2 & $0,32-0,52$ & 910 & 40 & 50 & 1,53 & 2,70 & 43 & 0,05 & 0,02 & 0,03 \\
\hline EB & $0,52-0,83$ & 890 & 40 & 70 & 1,59 & 2,70 & 41 & 0,05 & 0,02 & 0,03 \\
\hline $2 \mathrm{Btg}_{1}$ & $0,83-1,05$ & 880 & 10 & 110 & 1,59 & 2,67 & 40 & 0,27 & 0,20 & 0,07 \\
\hline
\end{tabular}

A diferença na textura entre as camadas de $0-80$ e $80-100 \mathrm{~cm}$ influenciou fortemente as curvas características da solução do solo (Figura 2), tanto que na primeira camada o melhor ajuste aos dados foi obtido pelo modelo de Brooks e Corey (1964), enquanto que na segunda o melhor foi o modelo potência.

Como conseqüência do predomínio praticamente absoluto da fração areia, constata-se a baixa capacidade de retenção de água do solo, sobretudo na camada de 0-80 $\mathrm{cm}$ (Figura 2), impondo à cultura um ambiente de alta freqüência de estresse hídrico. Analisando os dados de porosidade total $(\mathrm{Pt}) \mathrm{e}$ capacidade de campo (CC) na Tabela 1 e adotando esta última como uma estimativa aproximada da microporosidade, constata-se o grande predomínio da macroporosidade $(\alpha=\mathrm{Pt}-\mathrm{CC})$, a qual, nos primeiros $80 \mathrm{~cm}$ de profundidade, variou entre 79 e $88 \%$ da porosidade total. A partir de $80 \mathrm{~cm}$, como conseqüência do aumento do conteúdo de argila e pela ocorrência de estrutura com fraca agregação e de aspecto maciço (Ramos et al., 1973), observa-se o aumento da ocorrência de microporos (66\% da porosidade total).

Pelos valores de Água Disponível Total (ADT), constata-se que os pontos do solo com menor restrição hídrica para a planta estão nas profundidades de $80-100 \mathrm{~cm}$ e de $0-30 \mathrm{~cm}$, respectivamente (Tabela 1). O primeiro em conseqüência do aumento do teor de argila e maior adensamento, e o segundo pela presença de teores mais elevados de matéria orgânica (Balieiro, 2002).

\section{Alocação da biomassa de raízes}

Em média, cada árvore amostrada acumulou $8,8 \mathrm{~kg}$ de biomassa em suas raízes, o que equivale a $29,5 \mathrm{Mg} \mathrm{ha}^{-1}$. Destes, $57 \%$ representavam a raiz pivotante (Figura 3) e o restante $(43 \%$ ), as raízes mais finas amostradas nas trincheiras abertas na entrelinha. Em termos de acumulação de biomassa, a estimativa feita $\left(29,5 \mathrm{Mg} \mathrm{ha}^{-1}\right)$ é razoável se comparada com florestas tropicais e plantios em regiões tropicais. Cuevas et al. (1991), avaliando uma floresta secundária em Porto Rico, com 11 anos de idade, 
chegaram a valores de $10,5 \mathrm{Mg} \mathrm{ha}^{-1}$ de raízes finas $(<2 \mathrm{~mm})$, ao passo que no presente estudo, as raízes mais finas representaram $12,7 \mathrm{Mg} \mathrm{ha}^{-1}$. Reis et al. (1985), utilizando metodologia semelhante à usada no presente estudo, detectaram acumulação de 13,0 e 16,0 $\mathrm{Mg} \mathrm{ha}^{-1}$ de raízes (grossas e finas) pelo eucalipto em sítio de alta e baixa fertilidade, respectivamente.

A relação raiz/parte aérea da espécie, igual a 0,24 , é exatamente a mesma que a reportada por Cairns et al. (1997) após extensa revisão sobre a alocação de biomassa de raízes em florestas ao redor do mundo.
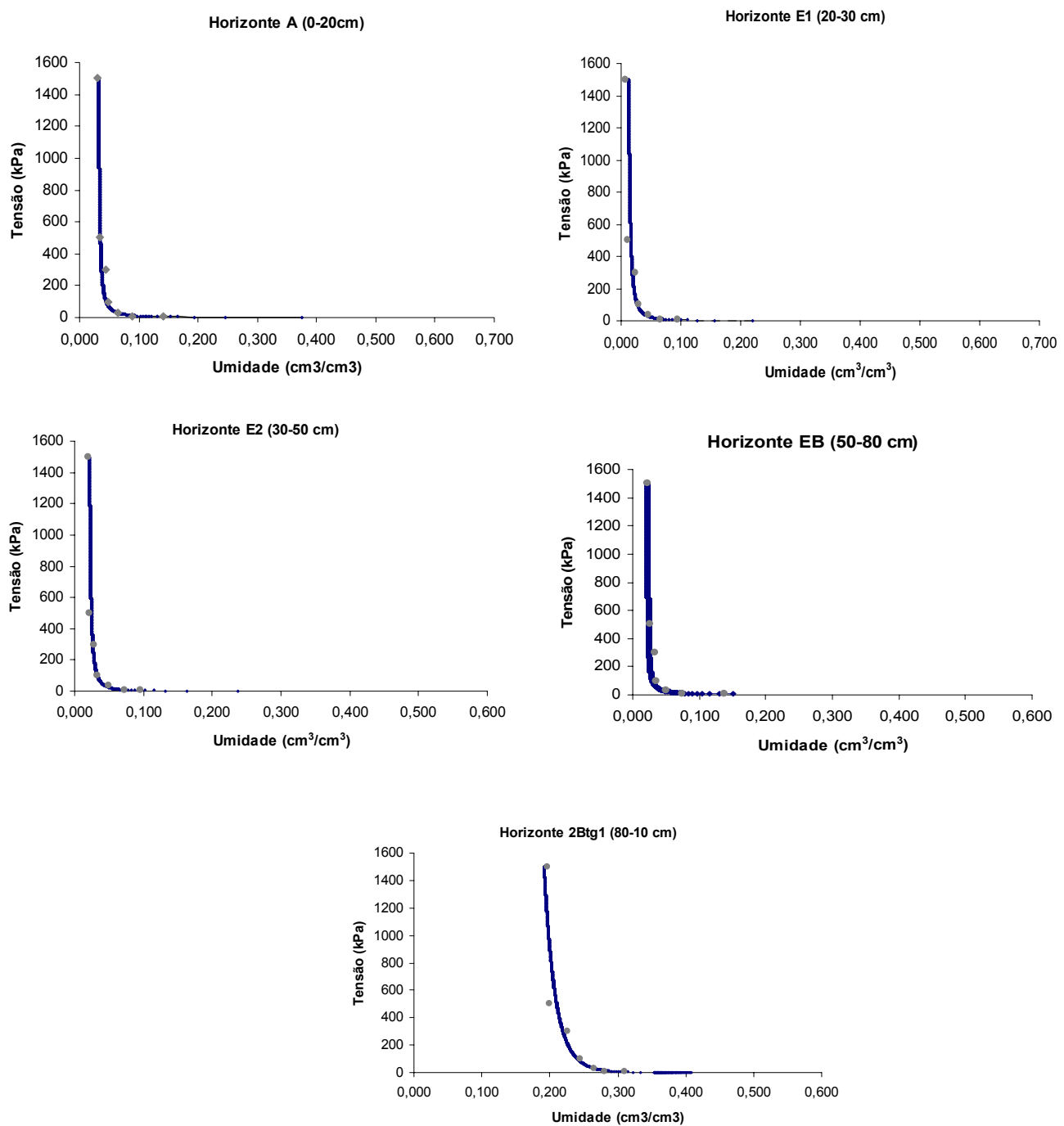

Figura 2. Curvas de retenção de umidade e modelos ajustados para cada horizonte amostrado. Figure 2. Soil water retention curves and adjusted models for each sampled layer.

\section{Distribuição das raízes no perfil}

A biomassa de raízes decresceu com a profundidade, independentemente do local de amostragem (Figura 4), sendo que cerca de $70 \%$ da massa de raízes estiveram associadas aos 20 primeiros centímetros de profundidade e possuíam diâmetro menor que $5 \mathrm{~mm}$. Esse comportamento evidencia a estratégia que as espécies tropicais usam para absorver de forma mais eficiente o nutriente ciclado via deposição de serapilheira, mantendo as raízes próximas à fonte de nutrientes. Essa evidência é bem nítida para o $\mathrm{P}$, pois 
as espécies florestais tropicais diminuem o contato desse elemento com a matriz do solo por meio de uma manta de raízes finas que povoam a serapilheira no solo. Assim, impedem que o "dreno-solo", que é bem mais forte que o "dreno-planta", torne o P mineralizado indisponível (Novais et al., 1998).
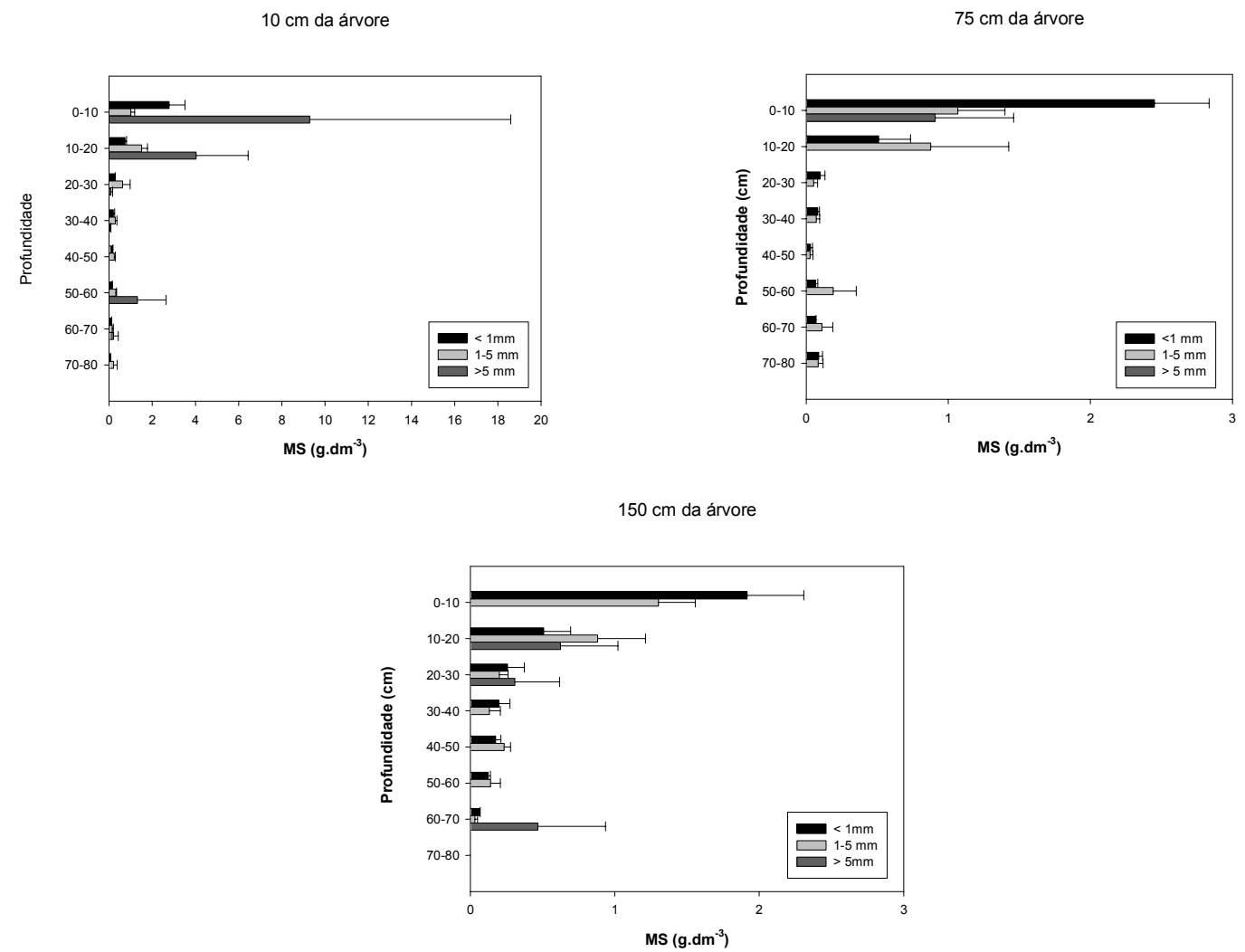

Figura 3. Distribuição da matéria seca das raízes (média \pm erro-padrão) ao longo do perfil nas diferentes distâncias e profundidades de amostragem.

Figura 3. Root dry biomass (average \pm standard error) soil distribution at different distance and depth of the sample.

Considerando a biomassa de raízes total, cerca de 60\% do total acumulado nessa camada (0-20 $\mathrm{cm}$ ) foram encontradas a $10 \mathrm{~cm}$ da árvore (Figura 4). Esse valor se relaciona com a significativa participação das raízes mais grossas, que dão sustentação à árvore.

As raízes mais finas tenderam a se distribuir mais homogeneamente nas demais distâncias do tronco (Figura 4). A participação elevada de raízes finas na maior distância do tronco (1,5 m) indica a possibilidade de interferência de árvores adjacentes na amostragem, mas não invalida o método por se saber que essa influência deve se dar de forma homogênea para todas as plantas.

\section{Regime hídrico do solo}

As figuras $5 \mathrm{~A}$ e $\mathrm{B}$ e $6 \mathrm{~A}$ e $\mathrm{B}$ apresentam os dados de variação da umidade do solo em profundidade, em intervalos semanais, nos meses de outubro e novembro. Optou-se por discutir os resultados de regime hídrico do solo para cada mês separadamente, devido às diferenças na altura de chuva incidente: no mês de outubro, $33 \mathrm{~mm}$; no mês de novembro, $115 \mathrm{~mm}$. No mês de outubro, observase que a umidade diminuiu com amplitude de $0,04-0,001 \mathrm{~cm}^{3} \cdot \mathrm{cm}^{-3}$ na entrelinha da cultura, e $0,06-0,017$ $\mathrm{cm}^{3} \cdot \mathrm{cm}^{-3}$ na linha. Esses valores muito baixos são explicados pela baixa pluviosidade no período, associada à textura arenosa do solo, sobretudo nos primeiros $80 \mathrm{~cm}$ de profundidade. Esses valores são 
inferiores aos reportados por Leite et al. (1999) em plantios de Eucalyptus grandis em solos cuja textura dos horizontes superficiais variava entre arenosa a franco-argilo-arenosa.

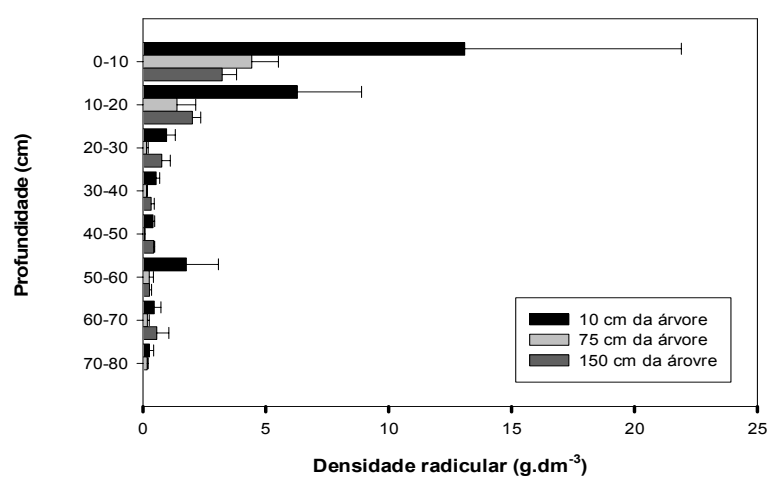

Figura 4. Distribuição das raízes amostradas nas diferentes distâncias do tronco e profundidades do solo (linhas dentro das colunas representam o erro-padrão da média).

Figure 4. Root distribution under different distances among trunks and soil depth (average \pm standard error).

$\mathrm{Na}$ linha de cultivo (Figura 5), o potencial hídrico variou bastante no período analisado, sobretudo na profundidade até $20 \mathrm{~cm}$, contrastando de $42 \mathrm{kPa}$ no dia $2 / 10$ a mais de $1500 \mathrm{kPa}$ nos demais dias. No dia $2 / 10$, período em que ocorreu precipitação equivalente a $6,8 \mathrm{~mm}$, comparando-se com os demais dias, encontraram-se valores bem maiores de umidade até a profundidade de $50 \mathrm{~cm}$, permitindo à planta absorção de água com maior facilidade (potenciais hídricos mais próximos da Capacidade de Campo). A partir de $50 \mathrm{~cm}$ de profundidade, como a precipitação foi pouca, a variação de umidade praticamente não se refletiu em maiores profundidades, exceção para o dia 23/10, em que se observa uma provável recarga de água proveniente das camadas superiores. Ressalta-se a alta taxa de infiltração desse solo, em função da textura arenosa, o que permite que baixas precipitações possam alcançar camadas mais profundas rapidamente. Ainda no dia 23/10, ocorreu outra chuva de $6,6 \mathrm{~mm}$, podendo explicar os maiores valores de umidade do solo nesse dia, especificamente na camada de 50 a $80 \mathrm{~cm}$, quando comparados com os dias 9 e 16/10. Na entrelinha (Figura 5), os valores de umidade são sistematicamente inferiores aos da linha de cultivo no que tange às camadas superficiais. A ocorrência de maiores valores de umidade próximo às árvores é explicada pelo efeito da participação do escoamento pelo tronco. Segundo Balieiro et al. (2001b), a contribuição desse escoamento para a espécie atinge valores de $9,4 \%$ do total precipitado. Como conseqüência da menor entrada de água na entrelinha, encontraram-se nesses locais valores menores de potencial hídrico, sobretudo na profundidade de $20 \mathrm{~cm}$, onde as suç̧ões se mantiveram maiores que $1500 \mathrm{kPa}$, em todo o período. De forma similar à linha de cultura, a umidade flutuou mais nos primeiros $50 \mathrm{~cm}$, não havendo alterações a $80 \mathrm{~cm}$.

Os dados referentes ao monitoramento em novembro (Figura 6) também demonstram que as maiores variações de umidade ocorrem na faixa de $0-50 \mathrm{~cm}$ tanto na linha como na entrelinha de cultivo. No entanto, em função da maior precipitação ocorrida nesse período $(115 \mathrm{~mm})$, os valores de umidade são superiores tanto na linha como na entrelinha. Os dados desse período caracterizam bem a dinâmica da água no solo logo após um evento pluviométrico. Na camada de $0-50 \mathrm{~cm}$, ocorreu elevação da umidade no período de $6 / 11$ a 20/11, caracterizando as fases de entrada de água e transmissão para as camadas subjacentes. Essa transmissão é facilmente notada na camada de 80 a $100 \mathrm{~cm}$ quando se compara a umidade do solo no período entre 6/11 e 20/11. Esse comportamento se confirma tanto para as medições na linha como na entrelinha. Como observado no período de outubro, a entrada de água na linha de cultura foi maior do que na entrelinha (Figura 6).

A possibilidade da massa de raízes, que é maior próxima ao tronco, estar favorecendo a atenuação de nêutrons e assim mascarando as estimativas não pode ser descartada, na medida em que a curva de calibração que correlaciona contagem de nêutrons atenuados e umidade do solo foi 
confeccionada na entrelinha de plantio. Mas é bem verdade que as variações detectadas representam fielmente a atividade das raízes e das propriedades físicas do solo.

Linha

Unid. Vol $\left(\mathrm{cm}^{3} \mathrm{~cm}^{-3}\right)$

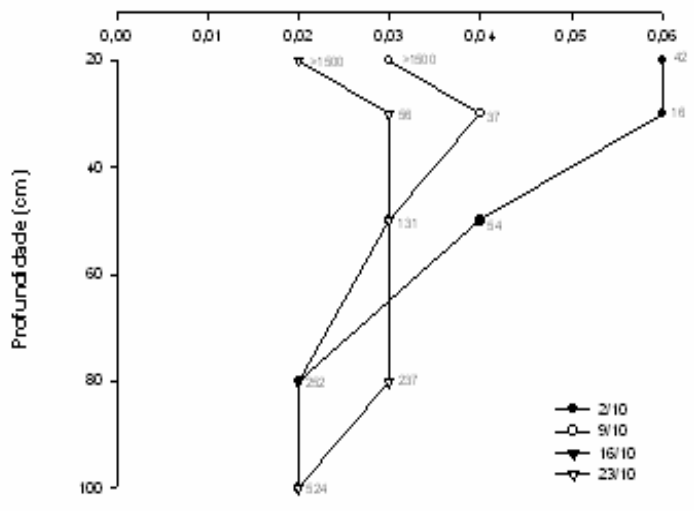

Entre-linha

Unid. Vol $\left(\mathrm{cm}^{3} \mathrm{~cm}^{-3}\right)$

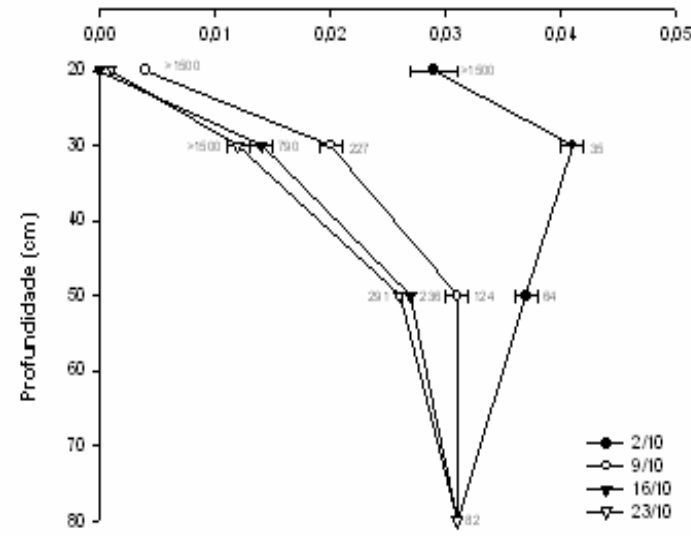

Figura 5. Variação da umidade volumétrica (linha e entrelinha) em profundidade nos intervalos semanais no mês de outubro.

Figure 5. Weekly variation of soilvolumetric humidity (line and between lines) at depth, in October.

UmId. Val. $\left(\mathrm{cm}_{\mathrm{cm}} \mathrm{cm}^{-2}\right)$

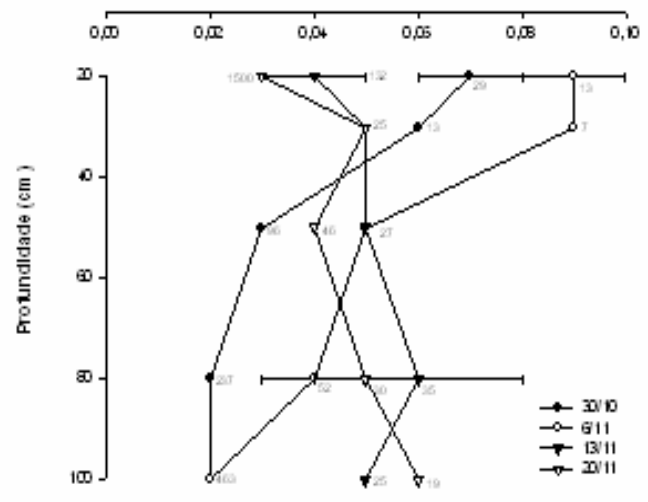

UmId. Vol. $\left(\mathrm{cm}^{-2-2}\right)$

$\begin{array}{rlllll}0,00 & 0,02 & 0,04 & 0,05 & 0,08 & 0,10\end{array}$

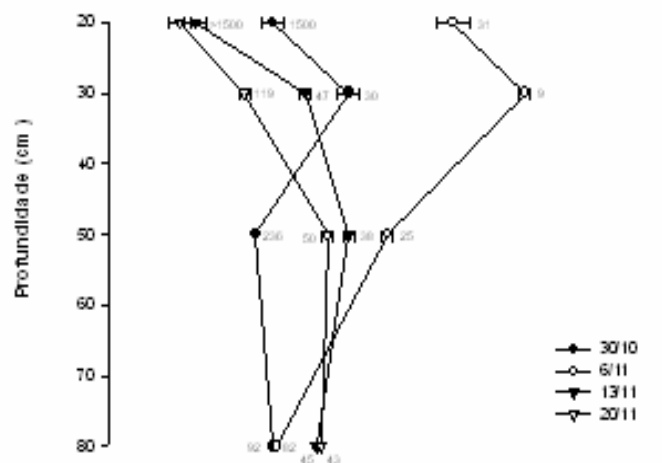

Figura 6. Variação da umidade volumétrica (linha e entrelinha) em profundidade nos intervalos semanais no mês de novembro.

Figure 6. Weekly variation of soil volumetric humidity (line and between lines) at depth, in November.

Esse comportamento confirma que a guachapele pode contribuir com o aumento da eficiência de uso de nutrientes e água na medida em que os obtém de maiores profundidades que aquelas comumente exploradas pelas raízes de culturas anuais. 


\section{CONCLUSÕES}

- A guachapele alocou $24 \%$ da sua biomassa total no sistema radicular, sendo que $70 \%$ da massa de raízes encontravam-se nos 20 primeiros centímetros de profundidade.

- As raízes finas, que compunham $43 \%$ do total das raízes, predominaram nos 20 primeiros centímetros e na entrelinha de cultivo.

- As variações de umidade indicam que o sistema radicular da guachapele modifica o regime hídrico do solo até a profundidade de $0,8 \mathrm{~m}$.

- O solo estudado apresenta características físico-hídricas que imprimem estresse hídrico freqüente às plantas.

\section{AGRADECIMENTOS}

Os autores agradecem ao CNPq e FAPERJ pelo apoio financeiro e bolsas concedidas para a execução deste trabalho.

\section{REFERÊNCIAS}

AWOTOYE, O. O.; ATAYESE, M. O.; OSONUBI, O.; MULONGOY, K.; OKALI, D. U. U.; Response of some tropical nitrogen-fixing woody legumes to drought and inoculation with mycorrhiza. In:. MULONGOY, K.; GUEYE, M.; SPENCER, D. S. C. (Eds.). Biological Nitrogen Fixation and Sustainability of Tropical Agriculture, Chichester: J. Willey \& Sons, 1992. p.67-76.

BACCHI, O. O. S.; REICHARDT, K. A sonda de nêutrons e seu uso na pesquisa agronômica, Piracicaba: USP/CENA, (Boletim Didático, 22), 1990.

BALIEIRO, F. C.; OLIVEIRA, I. G.; DIAS, L. E.; Formação de mudas de Acacia holocericea e A. auriculiformis: resposta à calagem, fósforo, potássio e enxofre. Revista Árvore, Viçosa, MG, v.25, p.183-191, 2001a.

BAlieiro, F. de C.; CUNHA, C. F. da; MOTTA, A. F.; FRANCO, A. A. Avaliação de um coletor de água de escoamento pelo tronco. Revista Arvore, Viçosa, MG, v.25, p.167-173, $2001 \mathrm{~b}$.

BALIEIRO, F. C. Dinâmica de nutrientes e da água em plantios puros e consorciado de Pseudosamanea guachapele Dugand e Eucalyptus grandis W. Hill ex Maiden. Seropédica, 2002. 121p., Tese (Doutorado). UFRRJ.

BALIEIRO, F. C.; FRANCO, A. A.; PEREIRA, M. G.; DIAS, L. E.; CAMPELlO, E. F. C.; FARIA, S. M. Dinâmica da serapilheira e transferência de nitrogênio ao solo, em plantios de Pseudosamanea guachapele e Eucalyptus grandis. Pesquisa Agropecuária Brasileira, Brasília,.v.39. p.597-601, 2004.

BROOKS, R. H.; COREY, A. T. Hydraulic Properties of Porous Media, Colorado State Univ./Civil Engineering Dept., Fort, 1964. Hydrologic Paper 3.

CAIRNS, M. A.; BROWN, S.; HELMER, E. H.; BAUMGARDNER. G. A. Root biomass allocation in the world's upland forests. Oecologia, New York, n.111, p.1-11, 1997.

CUEVAS, E.; BROWN, S.; LUGO, A. E. Above and below organic matter storage and production in a tropical pine plantation and a paired broadleaf secondary forest. Plant and Soil, Netherlands, v.135, p.257-268, 1991.

DIAS, L. E.; ALVAREZ V. V. H.; BRIENZA JR., S. Formação de mudas de Acacia mangium. I. Resposta à calcário e fósforo. Congresso Brasileiro Florestal, 6, 1990, Campos do Jordão SBCS/SBEF, 1990. p.449-453.

DIAS, L. E.; ALVAREZ V. V. H.; BRIENZA JR., S. Formação de mudas de Taxi-branco (Sclerolobium paniculatum). Resposta a calcário e fósforo. Pesquisa Agropecuária Brasileira, Brasília, v.26: p.69-76, 1991. 
DOURADO-NETO, D.; NIELSEN, D. R.; HOPMANS, J. W.; REICHARDT, K.; BACCHI, O. O. S. Software to model soil water retention curves (SWRC, version 2.00). Scientia Agrícola, Piracicaba, v.57: p.191-192, 2000.

EMBRAPA Centro Nacional de Pesquisa em Solos. Manual de métodos de análise de solo, Rio de Janeiro, 1997.

EMBRAPA. Centro Nacional de Pesquisa de Solos. Sistema brasileiro de classificação de solos, Rio de Janeiro, 1999.

FARIA, S. M.; LIMA, H. C.; OLIVARES, F. L.; MELO, R. B.; XAVIER, R. P. Nodulação em espécies florestais, especificidade hospedeira e implicações na sistemática de leguminosae. In: FERTBIO 98 Inter-relação fertilidade, biologia do solo e nutrição de plantas, SIQUEIRA, J. O., MOREIRIA, F. M. S., LOPES, A. S., GUILHERME, L. R. G., FAQUIN, V., FURTINI NETO, A. E., CARVALHO, J. G. (Eds.). Viçosa: SBCS, Lavras: UFLA/DCS, p.667-686, 1999.

FERNÁNDEZ, J. Q. P.; RUIVO, M. L. P.; DIAS, L. E.; COSTA, J. P. V.; DIAZ, R. R. Crescimento de mudas de Mimosa tenuiflora submetidas a diferentes níveis de calagem e doses de fósforo, potássio e enxofre. Revista Árvore, Viçosa, MG, v.20: p.425-431, 1996.

FRANCO, A. A.; FARIA, S. M. The contribution of $\mathrm{N}_{2}$-fixing tree legumes to land reclamation and sustainability in the tropics. Soil Biol. Biochem, Oxford, v.29: p.897-903, 1997.

FROUFE, L. C. M. Decomposição de serapilheira e aporte de nutrientes em plantios puros e consorciados de Eucalyptus grandis Maiden, Pseudosamanea guachapele Dugand e Acacia mangium Willd. Seropédica, 1999 Dissertação(Mestrado), UFRRJ.

JESUS, E. L.; de Seleção de leguminosas para adubação com maior capacidade de acidificação da rizosfera. Seropédica: UFRuralRJ, 1993. (Dissertação de mestrado)

LEITE, F. P.; BARROS, N. F.; NOVAIS, R. F.; SANS, L. M. A.; FABRES, A. S. Relações hídricas em povoamento de eucalipto com diferentes densidades populacionais. Revista Brasileira Ciência do Solo, Viçosa, MG, v.23: p.9-16, 1999.

MACEDO, I. C.; KOLLER, H. W. Balanço de energia na produção de cana de açúcar e álcool nas usinas cooperadas em 1996. International report, Centro tecnológico da Coopeçucar, Piracibaca: 1997.

NOVAIS, R. F.; SMYTH, T. J.; BARROS, N. F. A natureza não tem palito de fósforo! Queima rápida ou mineralização lenta (nem sempre tão lenta) de resíduos florestais. Boletim Informativo da SBCS, Viçosa, MG, v.23, p.22-29, 1998.

PEOPLES, M. B.; CRASWELL, E. T. Biological nitrogen fixation: investments, expectations and actual contributions to agriculture. Plant and Soil, Oxford, v.141, p.13-39, 1992.

SIQUEIRA, J. O.; FRANCO, A. A. Biologia do solo: fundamentos e perspectivas. Brasília: MEC-ESAL - FAEPE- ABEAS, 1988.

SISTI, C. P. J.; SANTOS, H. P.; KOHHANN, R.; ALVES, B. J. R.; URQUIAGA, S.; BODDEY, R. M. Change in carbon and nitrogen stocks in soil under 13 years of conventional or zero tillage in southern Brazil. Soil and Tillage Research, Netherlands, v.76, p.39-58, 2004.

RAMOS, D. P.; CASTRO, A. F. de; CAMARGO, M. N. Levantamento detalhado de solos da área da Universidade Federal Rural do Rio de Janeiro. Pesquisa Agropecuária Brasileira, (Série Agronomia), Rio de Janeiro, v.8, p.1-27, 1973..

REIS, M. G. F.; KIMMINS, J. P.; REZENDE, G. C.; BARROS, N. F. Acúmulo de biomassa em uma seqüência de idades de Eucalyptus grandis plantado no Cerrado em duas áreas com diferentes produtividades. Revista Árvore, Viçosa, MG, v.9, p.149-162, 1985.

REICHART, K.; TIMM, L. C. Solo, Planta e Atmosfera: conceitos, processos e aplicações. Barueri, SP: Manole, 2004. 